\title{
KEARIFAN LOKAL DALAM PENGOBATAN TRADISIONAL MASYARAKAT DESA LUMBUNGSARI KECAMATAN LUMBUNG KABUPATEN CIAMIS
}

\author{
Eka Kurnia Firmansyah \\ Maman Sutirman \\ Endang Baihaqie \\ Fakultas Ilmu Budaya Universitas Padjadjaran
}

\begin{abstract}
ABSTRAK
Pengobatan tradisional merupakan perwujudan suatu tatanan kearifan lokal di antaranya untuk menjaga keseimbangan hidup. Fokus dan tujuan penelitian ini adalah inventarisasi pengobatan tradisional yang digunakan oleh masyarakat Desa Lumbungsari, mendeskripsikan bentuk penggunaan dan manfaat pengobatan tradisional, dan memetakan potensi bagi pengembangan manfaat pengobatan tradisional. Kini pengobatan tradisional ini digencarkan penggunaannya oleh masyarakat karena lebih mudah dijangkau, baik harga maupun ketersediaannya. Obat tradisional saat ini banyak digunakan karena menurut beberapa penelitian tidak terlalu menyebabkan efek samping dan masih bisa dicerna oleh tubuh. Metode penelitian yang digunakan bersandar pada pendekatan deskriptif kualitatif dengan teknik etnografi. Hasil penelitian menunjukkan bahwa Pengobatan Tradisional Herbal di Kecamatan Lumbung memiliki beragam jenis pengobatan di antaranya: 1. Pengobatan Hikmah, 2. Pengobatan Menggunakan Jasa Paraji, 3. Pengobatan Tradisional Menggunakan Jasa Pijat, dan 4. Pengobatan Tradisional Menggunakan Herbal. Simpulan penelitian ini adalah penggunaan pengobatan tradisional, baik sebagai obat maupun tujuan lain cenderung meningkat, terlebih dengan adanya isu back to nature serta krisis berkepanjangan yang mengakibatkan turunnya daya beli masyarakat. Obat tradisional dan tanaman obat banyak digunakan masyarakat menengah ke bawah terutama dalam upaya preventif, promotif, dan rehabilitatif.
\end{abstract}

Kata kunci : Kearifan Lokal, Pengobatan Tradisional, Kesehatan

\begin{abstract}
Traditional medicine is an embodiment of an order of local wisdom such as to maintain the balance of life. The focus and purpose of this research is an inventory of traditional medicine that is used by the society of Lumbungsari village, describing the form of use and benefits of traditional medicine, and mapping the potential for development of traditional medicine benefits, where now widely used by the public as more easily accessible, both price and availability. Traditional medicine is widely used at this time because according to some studies, this does not cause side effects, also it can be digested by the body. The research methods used is a qualitative descriptive approach with ethnographic techniques. The results of this research show that the traditional herbal medicine in Lumbung districts has various types of treatment including: 1. The treatment of wisdom, 2. The treatment using the Paraji services, 3. The traditional treatment using massage services, 4 . The traditional treatment using herbal. As the conclusions it could be seen that the use of traditional medicine, both as a medicine and other purposes are likely to increase, especially with the issue of back to nature as well as the prolonged crisis which causes a decline in purchasing power of people. Traditional medicine and medicinal plants are widely used by the middle to low class society, especially in preventive, promotive, and rehabilitative efforts.
\end{abstract} Keywords: Local Wisdom, Traditional Medicine, and Health 


\section{PENDAHULUAN}

Bangsa Indonesia merupakan bangsa yang majemuk. Masyarakatnya terdiri dari berbagai macam suku bangsa yang tersebar di seluruh kawasan Nusantara. Setiap suku di setiap daerah memiliki kebudayaan yang dikembangkan secara turun-temurun. Kemajemukan budaya yang dimiliki setiap suku pada dasarnya merupakan kekayaan bangsa Indonesia. Berdasarkan realitas, kekayaan budaya yang dimiliki oleh bangsa Indonesia banyak yang belum dikembangkan secara proporsional. Dalam arti lain, belum sepenuhnya menyentuh masyarakat sebagai media penumbuhan jati diri bangsa dan sebagai sumber potensi diri.

Keragaman budaya sejatinya dapat dijadikan modal untuk memperkuat identitas kebangsaan. Di samping itu, keragaman budaya termasuk kesenian dimungkinkan dapat dijadikan komoditas nasional yang dapat memberikan kontribusi bagi kesejahteraan masyarakat. Bali misalnya, merupakan salah satu contoh wilayah yang menjadikan produk budaya masyarakatnya sebagai komoditas yang laku dijual. Kontribusi produk budaya seperti kesenian tradisional di Bali hendaknya dijadikan inspirasi bagi daerah-daerah lain di Nusantara.

Pelestarian budaya secara umum dapat didefinisikan segala perilaku atau tindakan (upaya) yang bertujuan untuk mempertahankan keadaan dan keberadaan suatu peninggalan generasi masa lampau melalui proses inventarisasi, dokumentasi, dan revitalisasi. Salah satu prioritas dalam pembangunan nasional adalah pelestarian (perlindungan, pemanfaatan, pemeliharaan, dan pengembangan) terhadap warisan budaya sebagai aset bangsa yang memiliki nilai sejarah, ilmu pengetahuan, dan ekonomi.

Pelestarian budaya tersebut bermanfaat dalam upaya:

1) Untuk mengetahui, memahami, dan menghargai prestasi-prestasi atau pencapaianpencapaian nenek moyang sebuah masyarakat atau bangsa.

2) Menjadi sumber inspirasi untuk membangun masa depan yang lebih baik tanpa mengulangi kesalahan masa lalu.

3) Menjadikan deposi yang dapat dimanfaatkan untuk meningkatkan kesejahteraan masyarakat karena tinggalan budaya merupakan saksi sejarah perjalanan bangsa Indonesia dari zaman ke zaman dengan berbagai kondisi perkembangan dunia.

Kebudayaan merupakan salah satu perwujudan jati diri bangsa yang mempunyai ciri khas dari gambaran kehidupan masyarakat Indonesia dari berbagai etnik. Kelangsungan hidup sebuah bentuk tradisi kebudayaan khususnya pengobatan tradisional agar tetap hidup dan berkembang sangat ditentukan oleh peranan kebijakan pemerintah dan kepedulian masyarakat.

Masing-masing komponen pemerintah, masyarakat, pewaris/ahli waris, kaum agamawan, dan budayawan, mempunyai peranan sendiri-sendiri, namun saling terkait dalam upaya pelestarian suatu tinggalan budaya. Demikian juga dengan pelestarian pengobatan tradisional yang terdapat di Desa Lumbungsari Kecamatan Lumbung Kabupaten Ciamis Provinsi Jawa Barat.

Lumbung merupakan salah satu kecamatan yang berada di kabupaten Ciamis Jawa Barat yang memiliki banyak sejarah, budaya, dan kekhasan. Permasalahan yang ada mengenai pengobatan tradisional herbal berdasarkan informasi dari aparat kecamatan dan petugas di puskesmas desa bahwa kondisi pemanfaatan pengobatan tradisional sangat memprihatinkan. Dari sekian inventarisasi yang ada hanya ada beberapa orang saja yang masih menggunakan pengobatan tradisional.

Hal tersebut berdasar pada tingkat kebutuhan masyarakat terhadap obatobatan kimia yang didapat dari puskesmas atau pelayanan kesehatan lainnya yang lebih menjanjikan untuk dapat kembali sehat daripada menggunakan pengobatan tardisional herbal yang terhitung ribet dan lama dalam hal proses pengobatan/ penyembuhan. 


\section{METODE}

Metode yang digunakan pada penelitian ini adalah metode kualitatif. Oetomo (2005:186) mengungkapkan bahwa data kualitatif dapat dikumpulkan melalui tiga cara: 1. Wawancara. Hasil data yang diperoleh adalah ungkapan langsung dari narasumber/ informan tentang pengalaman, pendapat, dan pengetahuannya.

2. Observasi langsung. Hasil yang diperoleh dari cara ini adalah rincian pengamatan tentang kegiatan, perilaku, dan tindakan individu atau sekelompok masyarakat yang terkait dengan tema, dan judul penelitian.

3. Penelaahan dokumen tertulis. Data yang dihasilkan berupa cuplikan, kutipan, atau penggalan catatan referensi yang berkaitan dengan tema penelitian.

Dalam kegiatan penelitian ini, ketiga cara tersebut digunakan: wawancara diperlukan untuk mendukung data faktual yang ada pada dokumen tertulis atau pencarian melalui internet; observasi langsung sangat diperlukan untuk pendokumenan data yang belum lengkap.

Penelitian ini dilaksanakan di wilayah Desa Lumbunsari Kecamatan Lumbung. Wilayah ini sangat representatif sebagai sampel untuk dapat mewakili objek penelitian.

Obat tradisional adalah obat-obatan yang diolah secara tradisional, turuntemurun, berdasarkan resep nenek moyang, adat-istiadat, kepercayaan, atau kebiasaan setempat, baik bersifat magic maupun pengetahuan tradisional. Menurut penelitian masa kini, obat-obatan tradisional memang bermanfaat bagi kesehatan, dan kini digencarkan penggunaannya karena lebih mudah dijangkau masyarakat, baik harga maupun ketersediaannya. Obat tradisional pada saat ini banyak digunakan karena menurut beberapa penelitian tidak terlalu menyebabkan efek samping dan masih bisa dicerna oleh tubuh.

Beberapa perusahaan mengolah obat-obatan tradisional yang dimodifikasi lebih lanjut. Media dan bagian dari obat tradisional yang bisa dimanfaatkan adalah air putih, akar, rimpang, batang, buah, daun, dan bunga.

Penggunaan bahan alam, baik sebagai obat maupun tujuan lain cenderung meningkat, terlebih dengan adanya isu back to nature serta krisis berkepanjangan yang mengakibatkan turunnya daya beli masyarakat. Obat tradisional dan tanaman obat banyak digunakan masyarakat menengah kebawah terutama dalam upaya preventif, promotif dan rehabilitatif. Sementara ini banyak orang beranggapan bahwa penggunaan tanaman obat atau obat tradisional relatif lebih aman dibandingkan obat sintesis. Walaupun demikian bukan berarti tanaman obat atau obat tardisional tidak memiliki efek samping yang merugikan, bila penggunaannya kurang tepat. Agar penggunaannya optimal, perlu diketahui informasi yang memadai tentang kelebihan dan kelemahan serta kemungkinan penyalahgunaan obat tradisional dan tanaman obat. Dengan informasi yang cukup diharapkan masyarakat lebih cermat untuk memilih dan menggunakan suatu produk obat tradisional atau tumbuhan obat dalam upaya kesehatan.

Efek samping obat tradisional relatif kecil jika digunakan secara tepat, yang meliputi:

- Kebenaran bahan, tanaman obat di Indonesia terdiri dari beragam spesies yang kadang kala sulit untuk dibedakan satu dengan yang lain. Kebenaran bahan menentukan tercapai atau tidaknya efek terapi yang diinginkan.

- Ketepatan dosis, tanaman obat, seperti halnya obat buatan pabrik memang tak bisa dikonsumsi sembarangan. Tetap ada dosis yang harus dipatuhi, seperti halnya resep dokter. Buah mahkota dewa, misalnya, hanya boleh dikonsumsi dengan perbandingan 1 buah dalam 3 gelas air, sedangkan daun mindi baru berkhasiat jika direbus sebanyak 7 lembar dalam takaran air tertentu. 
- Ketepatan waktu penggunaan, misalnya kunyit diketahui bermanfaat untuk mengurangi nyeri haid dan sudah turun-temurun dikonsumsi dalam ramuan jamu kunir asam yang sangat baik dikonsumsi saat datang bulan, Akan tetapi jika diminum pada awal masa kehamilan beresiko menyebabkan keguguran. Hal ini menunjukkan bahwa ketepatan waktu penggunaan obat tradisional menentukan tercapai atau tidaknya efek yang diharapkan.

- Ketepatan cara penggunaan, satu tanaman obat dapat memiliki banyak zat aktif yang berkhasiat di dalamnya. Masing-masing zat berkhasiat kemungkinan membutuhkan perlakuan yang berbeda dalam penggunaannya. Sebagai contoh adalah daun kecubung jika dihisap seperti rokok bersifat bronkodilator dan digunakan sebagai obat asma. Akan tetapi, jika diseduh dan diminum dapat menyebabkan keracunan/ mabuk.

- Ketepatan telaah informasi, perkembangan teknologi informasi saat ini mendorong derasnya arus informasi yang mudah untuk diakses. Informasi yang tidak didukung oleh pengetahuan dasar yang memadai dan telaah atau kajian yang cukup seringkali mendatangkan hal yang menyesatkan. Ketidaktahuan bisa menyebabkan obat tradisional berbalik menjadi bahan membahayakan.

\section{HASIL DAN BAHASAN}

Hasil wawancara dan observasi langsung kepada masyarakat khususnya kepada para narasumber di Desa Lumbungsari Kecamatan Lumbung Kabupaten Ciamis menunjukkan bahwa pelayanan kesehatan bagi masyarakat sudah memadai dan terlayani dengan baik, sehingga pengobatan tradisional yang menggunakan tumbuh-tumbuhan atau herbal sudah jarang dipakai/ digunakan.

Selanjutnya, penulis menemukan beberapa orang di Desa Lumbungsari yang ternyata masih menggunakan pengobatan tradisional, bahkan penggunaannya masih diyakini dapat menyembuhkan beberapa penyakit. Mereka yakin bahwa obat-obatan kimia pada dasarnya berasal dari tumbuhan dan sangat mudah didapat di sekitar lingkungan kita, namun kurangnya pengetahuan masyarakat saja yang tidak tahu betapa pentingnya tumbuh-tumbuhan yang mereka tanam.

Dalam hal inventerarisasi pengobatan tradisional ini, penulis mewawancarai dan mengobservasi langsung dengan narasumber atau sesepuh yang masih menggunakan pengobatan tradisional di antaranya :

a) Pengobatan dengan menggunakan cara ilmu Hikmah

b) Dukun Beranak (paraji)

c) Pijat Refleksi

d) Pengobatan Tradisional Hebal

\section{Pengobatan Tradisional Menggunakan Ilmu Hikmah} sebagai berikut:

Pengobatan tradisional dengan menggunakan ilmu hikmah ini rinciannya

a) Tokoh Al-Hikmah : Kuwu Maman (Kepala Desa Lumbungsari)

b) Perolehan cara pengobatan : Pernah mesantren di salah satu pesantren Dukuh di daerah Kadugede Kabupaten Kuningan Jawa Barat, pernah belajar juga dengan sesepuh desa bernama (alm) Bp. Sukaemi

c) Sumber ilmu hikmah : Kitab Syamsul Ma'arif

d) Media yang digunakan : Pengantar air putih

e) Hal-hal yang bisa ditangani (keluhan pasien yang datang): 


\section{1) Sakit lambung}

Caranya adalah dengan membaca doa sambil ditiupkan ke air putih. Berikut doanya:

$$
\text { اللهم بعزته و قدرته إن فى ذللك لآيات لكل صبار شكور }
$$

"Allahumma bi 'izzatihi wa qudratihi inna fii dzaalika la aayaatin likulli shobbarin syakuur"

2) Kerasukan Jin

Membaca doa sambil ditiupkan ke telinganya tiga kali. Berikut doanya:

$$
\text { يا حضرة شيخ قطب العالم المحي الحق و الدين شيخ عبد القادر الكيلانى }
$$

"Yaa hadlroti syaikh quthbal 'aalam al-muhyi al-haqqi wa al-diini syaikh abdul qodir al-kaylaani"

3) Susah meninggal

Menyiapkan air terlebih dahulu sambil dibacakan doa setelah itu ditiupkan ke pasien untuk diminumkan lalu diusapkan ke sekujur tubuh dari atas sampai kaki, setelah sampai kaki dicipratkan keluar. Aternatif lain dari penanganan ini adalah dengan cara mengambil tanah segenggam dari kuburan orang tuanya, lalu tanahnya diseduh/ disaring dengan air sampai jernih lalu diminumkan Berikut doanya:

'Allahumma waliyyud dunya yaa shobbaru wa muntakaa yaa kammaan"

4) Kehilangan barang

Sebelum berdoa membaca fatihah dulu khusus untuk malaikat Mikail, lalu membaca surat al-thariq sebanyak 84 kali, bacaan pertama dan terakhir ditamatkan membaca sampai akhir surat, adapun yang 82 sisanya hanya dibaca sampai "daafiq" atau dibaca hanya 6 ayat saja.

5) Bagi yang susah melahirkan

Sebelum berdoa membaca fatihah dulu khusus untuk malaikat Malakul Arhaam. Berikut doanya:

$$
\text { اللهم يخرج من بطون امهاتكم تارة اخرى }
$$

"Allahumma yakhruju min buthuuni ummahaatikum taarotan ukhroo" (doa ini juga bisa dipakai untuk mijahkeun/ mengawinkan ikan)

6) Anak yang sering menangis atau demam

Membaca doa sambil ditiupkan ke air putih untuk diminumkan ke pasien lalu di basuhkan ke muka anak tersebut oleh ibunya. Alternatif lain adalah dengan membacakan doa berikut:

بسم الله يرقيك و الله يشفيك من كل داء يأتيك من شر النفاتات فى العقد و من شر حاسد إذا حسد

"Bismillahi yarqiika wa Allahu yusyfiika min kulli daa'in ya'tiika min syarrin naffaasaati fil 'uqod wa min syarri haasidin idzaa hasad"

7) Amalan bagi pasien

Membaca fatihah khusus bagi Nabi Yunus lalu membaca doa sebanyak 41 kali setelah sholat ashar, ditiupkan ke air putih lalu diminumkan. Berikut doanya:

$$
\text { لا اله الا انت سبحانك إنى كنت من الظالمين }
$$

"laa ilaaha illaa anta subhaanaka innii kuntu minadz dzolimiin" 
8) Bagi yang ingin dunia atau mempunyai hajat/ keperluan

Harus berusaha, dan mengamalkan bacaan surat Waqi'ah 113 kali bisa dibaca oleh jama'ah per orang/ 1 surat lalu membaca doa sebanyak 113 kali. Berikut doanya:

\section{9) Membuka kunci/ gembok}

$$
\text { "Bismillahi al-waarits" بسم الله الوارث }
$$

Keahlian ini tidak bisa dipraktikkan semua orang, namun caranya adalah membaca doa sambil ditiupkan ke kunci sebanyak 41 kali. Berikut doanya;

$$
\text { و الله من ورائهم محيط بل هو قرآن مجيد فى لوح محفوظ }
$$

"Wa Allahu min waraa' ihim muhiith bal huwa qur'aanun majiid fii lauhin mahfuudz"

10) Menaklukkan orang yang keras kepala/ bengal

Mengambil padi 7 butir, setiap mengambil per butir padi membaca doa sampai butir ke-tujuh lalu dibakar. Berikut doanya:

$$
\text { رب المشرق و المغرب لا اله الا هو فاتخذه وكيلا }
$$

"Robbul Masyriqi wa al-Maghribi laa ilaaha illaa huqa fat takhidzhu wakiilaa"

11. Jika maksud ingin tercapai maksud baik atau buruk (buruk tidak diperbolehkan) Membaca doa lalu ditulis di atas kertas, dilipat, setelah itu ditindihkan dengan menggunakan sesuatu beban yang berat. Berikut doanya:

$$
\text { انما أمره إذا اراد شيأ ان يقول له كن فيكون }
$$

"Innamaa amruhuu idzaa arooda syai'an an yaquula lahuu kun fayakuun"

\section{Pelet/ Asihan}

Menuliskan doanya lalu ditulis di atas daun cempaka lalu dibawa oleh yang bersangkutan agar banyak yang menyayangi. Berikut doanya:

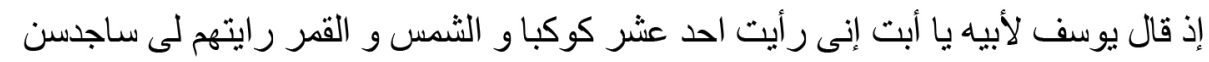

"idz qoola yusufli abiihi yaa abatii inni roaiytu ahada 'asyaro kawkaban was syamsa wal qomaro roaituhum lii saajidiin"

13. Mengobati Penyakit Eksim

Cara mengobatinya dengan menggunakan tape yang buruk ditempelkan langsung ke lukanya lalu baca doa. Berikut doanya:

$$
\text { اللهم بعزته و قدرته إن فى ذللك لآيات لكل صبار شكور }
$$

"Allahumma bi 'izzatihi wa qudratihi inna fii dzaalika la aayaatin likulli shobbarin syakuur"

14. Jika ingin disayangi pimpinan/ atasan

Membaca surat 12 kali lalu dilanjut dengan membaca doa. Berikut doanya;

$$
\text { إذ قال يوسف لأبيه يا أبت إنى رأيت احد عشر كوكباو الشمس و القمر رايتهم لى ساجدسن }
$$

"idz qoola yusufli abiihi yaa abatii inni roaiytu ahada 'asyaro kawkaban was syamsa wal qomaro roaituhum lii saajidiin"

15. Jika ingin tidak gentar terhadap musuh

Agar tidak grogi ketika akan pidato ketika berdiri membaca bacaan "jangjawokan" namun dibaca pelan. Berikut bacaannya;

"sia monyet kabeh aing mandahna"

16. Bagi yang ingin cepat punya keturunan

Mencari pisang saba dan asam kawak di jus lalu diminum oleh istrinya saja, lalu membaca doa: 


$$
\text { الحمد الله الذى خلق من الماء بشر ا فجعله نسباو سحر ا }
$$

"alhamdulillahi kholaqo minal maa'i basyaron fa ja'alahu nasaban wa sihron"

17. Ingin dimudahkan jodohnya

Doa ini khusus diberikan oleh bapa Kuwu, syaratnya orang tersebut harus meminta sisa air minum orang yang pulang bekerja, artinya untuk mengembalikan kotoran atau halangan yang ada pada diri orang yang susah jodohnya, caranya didoakan dahulu airnya lalu diminum. Berikut doanya:

إذ قال يوسف لأبيه يا أبت إنى رأيت احد عشر كوكباو الشمس و القرر رايتهم لى ساجدسن "idz qoola yusufli abiihi yaa abatii inni roaiytu ahada 'asyaro kawkaban was syamsa wal qomaro roaituhum lii saajidiin"

18. Jika ingin menang dalam berdebat

Syaratnya adalah berpuasa terlebih dahulu lalu membacakan jampe/ kejawen sambil mengepalkan tangan lalu diapit dengan paha ketika membaca kem, maka akan mingkem/ diam. Berikut bacaan yang diamalkan:

"Senen salasa rebo kem..."

19. Jika ingin menahan hujan atau kesenangan dunia

Membaca doa sebanyak 300 kali di tempat yang bersih/ suci, jika ingin bahagia baca doa setiap setelah sholat fardlu sebanyak 8 kali, berikut doanya, jika ingin awet muda baca doa 60 kali setiap hari kamis:

$$
\text { لا تدركه الأبصر و هو يدرك الأبصر و هو اللطيف الخبير }
$$

"laa tudrikuhul abshoru wa huwa yudrikul abshoro wa huwal lathiiful khobiir"

\section{Pengobatan oleh Praktisi Dukun Beranak/ Paraji}

Adapun praktisi pengobatan ini adalah:

a) Tokoh paraji: Ma Ining (ibu Ining)

b) Usia: 60 tahun

c) Alamat: Kp. Dayeuhdatar Desa Lumbungsari Kecamatan Lumbung Kab. Ciamis

d) Perolehan cara pengobatan: keahlian diperoleh dari orang tua (Mama Surya) dari Cirebon, belajar juga dari para sesepuh (nini beurang/paraji) dengan cara mengikuti praktik nini beurang jika ada pasien atau yang akan melahirkan.

e) Sumber keahlian: dari sesepuh nini beurang (paraji) bernama Ma (ibu) Ening yang tinggal di daerah kampung Cileungsing desa Lumbungsari

f) Media yang digunakan: pengantar air putih

g) Hal-hal yang bisa ditangani (keluhan pasien):



Gambar 1 Teknik pemijatan

\section{1) Jika ingin punya anak}

Cara pengobatan: bagi istri perut kandungan dipegang/ dipijat, bagi laki-laki dipijat di bagian belakang. Jika pinggang kurus dan sering sakit pinggang maka kandungan lakilaki kurang baik. Jika perempuan ketika akan haid suka merasa sakit atau merasa sakit di kandungan dapat diurut dan diperbaiki kandungannya, namun berdasarkan kekuasaan Allah juga. Ramuan yang dipakai agar subur kandungan adalah dengan air 
kelapa muda dan telur ayam kampung dicampur lalu diminum oleh suami dan istri yang ingin punya keturunan diminum 2 hari atau 3 hari sekali.

Atau jika ada pasien yang sudah banyak anak lalu tidak ingin punya keturunan maka kandungan isteri dipijat ke dalam sehingga tidak akan terjadi pembuahan.

2) Jika ingin kuat dalam hubungan suami isteri/ kejantanan (bagi yang kurang syahwat)

Cara pengobatan dipijat seperti contoh praktik di atas lalu membuat ramuan sirih hitam 2 lembar ditambah jahe hitam/ merah satu rimpang ditumbuk lalu dioleskan ke bagian perut bagi perempuan dan bagian belakang bagi laki-laki. Bagi laki-laki yang ingin tambah kejantanan ada ramuan yang diminum yaitu: nangka belanda, daun sirsak 7 lembar ditambah daun sirih hitam 2 lembar lalu direbus dan diminum.

3) Mengobati keputihan

Caranya adalah menyediakan 3 lembar daun sirih direbus, setelah hangat lalu disiramkan ke kemaluan perempuan, sebagian diminum 2 gelas. Adapun bagi yang keputihan dianjurkan untuk tidak memakan terasi dan mentimun karena akan menyebabkan keputihan bertambah parah.

4) Jika ada yang susah dalam melahirkan (keadaan sungsan)

Jika ada yang sungsang maka digedog atau diubah posisi bayinya di dalam kandungan ibu dengan cara diurut.

Sudah terbiasa Ma Paraji ini sebelum mengobati selalu menyiapkan air bagi pasien lalu berdoa tawasul terlebih dahulu sholat istikharah lalu membaca bacaan seperti berikut:

"Serepaningal naga wisesa dayana pinayungan nabi Adam Yahu Ya Allah Ya Muhammad Ya Rasulallah rasana kawula rasana Allah sok geura medal ulah ngeumbing kana tulang ulah ngeumbing kana daging geura sot borosot kaluar"

5) Jika ada anak/ bayi panas

Cara mengobatinya adalah diurut urat sarafnya dari belakang punggung, lambung dan sekujur tubuh, lalu diberi air untuk menghilangkan panas di badan dan diminumkan. Sambil dibacakan doa:

اللهم كافى محمد و كلمة سوالك محمد ببركة محمد صلى الله عليه و سلم برحمتلك يا ارحم الر احمين "Allahumma Kaafii Muhammad wa kalimati siwaaki Muhammad bi barakati Muhammad Shallallahu 'alaihi wa sallam bi rahmatika yaa Arhamar Raahimiin"

6) Jika ada anak/ bayi yang mencret

Cara mengobatinya adalah dengan cara di "cekok" dengan menggunakan campuran kuning pitih, kuning temen, pucuk daun jambu, daun kahitutan, daun sembung ditumbuk lalu dikukus diperas dan diambil airnya untuk dicekok ke anak/ bayi yang mencret.

7) Jika ada anak/ bayi yang suka menangis tanpa sebab/ atau anak ingin pintar, menurut/ patuh pada kedua orang tua

Diberi air putih untuk diminun, ketika anak tidur ditiupkan doa:

$$
\text { اللهم يا مغنى و أغنى بأهلك عن حرامك و أغنى بفضلك عن سواك }
$$

"Allahumma Yaa Mughnii wa aghnii bi ahlika 'an haraamika wa aghnii bifadllika 'amman siwaaka" 
8) Jika ada anak/ bayi yang susah makan

Cara mengobatinya adalah dengan menghadirkan makanan yang disukai anak tersebut lalu dibacakan doa:

$$
\begin{aligned}
& \text { لا اله الا الله أنت لا اله هو أنا لا اله إنى أخرى لا اله الا الله آمنا نبي الله لا اله الا الله } \\
& \text { يقينا نبي الله لا اله الا الله محمد رسول الله لا اله الا الله و لله برحمتلك يا ارحم الرالها احمين }
\end{aligned}
$$

"Laa ilaaha illa Allah anta Laa ilaaha huwa anaa La ilaaha innii ukhroo Laa ilaaha illa Allah aamannaa nabiyyallah Laa ilaaha illa Allah yaqiinan nabiyyallah Laa ilaaha illa Allah Muhammad rasuulallah Laa ilaaha illa Allah wa lillahi birahmatika yaa arhamar raahimiin"

9) Jika ada anak yang ingin disapih

Cara mengobatinya adalah dengan mengolesi "papaitan" sesuatu yang berasa pahit ke putting susu sang ibu agar anak tidak mau menyusui karena pahit, sambil membaca mantra/ doa, berikut bacaannya:

"Payureda gedang doka cakra Negara batara ngantai cot porocot tali peucang tampang pecleng"

\section{Pengobatan oleh praktisi pijat}

Adapun rincian pengobatan tradisional dengan cara pijat ini sebagai berikut:

a) Tokoh praktisi pijat: Yayan Sudaryanto

b) TTL: Banjarbaru 13 Februari 1966 (49 tahun)

c) Alamat: Kp. Bungursari Desa Lumbungsari Kecamatan Lumbung Kab. Ciamis

d) Perolehan cara pengobatan: keahlian diperoleh dari orang tua yang selalu berpindah tugas sebagai seorang tentara, pernah belajar juga tenaga dalam Prana Sakit di Depok.

e) Media yang digunakan: akar pohon yang sudah dibentuk sedemikian rupa dan minyak keletik dan doa

f) Hal-hal yang bisa ditangani: Ahli dalam memijat, bisa memijat pasien yang pegal linu, terkilir, atau ingin dilancarkan peredaran darah bahkan tentang kejantanan. Cara pengobatan adalah sebelum pemijatan dimulai dengan memanjatkan doa/ tawassul terlebih dahulu agar pasien yang akan dipijat diberikan kesembuhan.

\section{Pengobatan Tradisional Herbal}

Adapun rincian pengobatan tradisional herbal ini sebagai berikut:

a) Tokoh praktisi herbal : Yayan Sudaryanto

b) TTL: Banjarbaru 13 Februari 1966 (49 tahun)

c) Alamat: Kp. Bungursari Desa Lumbungsari Kecamatan Lumbung Kab. Ciamis

d) Perolehan cara pengobatan : keahlian diperoleh dari orang tua yang selalu berpindah tugas sebagai seorang tentara di tiap-tiap daerah.

e) Macam-macam tumbuhan/ herbal yang digunakan:

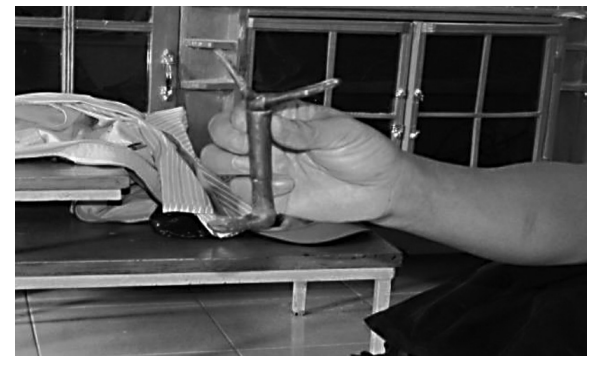

Gambar 2 media yang

digunakan untuk memijat

(akar) 


\section{Pala / Myristica Fragrans Houtt}

Khasiat dan manfaat:

a. Mengobati penyakit disentri, maag, mencret, menghentikan muntah, mual, mulas, perut kembung dan rematik.

Cara pemakaian bagi penyakit di atas:

Biji pala (serbuk) 1 gram, buah pisang batu (serbuk) 6 gram, air $100 \mathrm{ml}$ diseduh lalu diminum satu kali sehari $100 \mathrm{ml}$, diulang selama 30 hari/ sampai sembuh

b. Suara parau

Cara pemakaiannya: Biji pala (serbuk) 2 butir, rimpang jahe (diukur) 3 rimpang, bunga kuncup cengkeh (serbuk) 7 biji, air $50 \mathrm{ml}$ diseduh lalu diborehkan pada leher, bila perlu ditambah minyak kayu putih sedikit, diperbarui setiap 3 jam.

c. Vitalitas/ stamina

Cara pemakaian: Pala dibelah diambil bijinya lalu direbus dicampur dengan pinten, jahe dan kapolaga, diminum atau bisa dicampur air susu dan gula merah dimimun seperlunya

d. Pala dapat dibuat bumbu/ rempah-rempah

Adapun manfaat lainnya, pala muda untuk manisan dan pala yang tua dapat digunakan untuk rempah-rempah.

\section{Lengkuas/ Laja / Alpinia Galanga, Linn}

Bagian yang digunakan: rimpang

Khasiat dan manfaat:

a. Mengobati rematik, sakit limpa, gairah seks, nafsu makan

Cara pemakaian untuk penyakit di atas: 2 Rimpang laja diparut dan diperas untuk diambil airnya, telur ayam kampung mentah diambil kuningnya lalu dicampur sampai merata, diminum1 kali sehari.

b. Bronkhitis, morbili, panu, kadas kurap

Cara pemakaiannya: 2 Rimpang laja sebesar ibu jari, 3 rimpang umbi temulawak sebesar ibu jari dan 1 genggam daun meniran, bahan-bahan tersebut direbus ditambah tiga gelas air sampai mendidih, diminum 2 kali sehari 1 cangkir (pagi dan sore)

c. Menurunkan kolesterol

Cara pemakaiannya: daun sirih, salam dan lengkuas/ laja dicampur direbus dalam masakan agar berkhasiat menurunkan kolesterol yang ada pada masakan.

3. Jahe / Zingiber officinale Rosc.

Bagian yang digunakan: rimpang

Khasiat dan manfaat:

a. Mengobati batuk, membangkitkan nafsu makan

Cara pemakaiannya: Jahe diparut 3 rimpang, diperas lalu diminum 3 kali sehari 1 sendok teh diulang selama 3 hari

b. Mulas, perut kembung, gatal, luka, dan sakit kepala

Cara pemakaian: Jahe diparut 3 rimpang, pindahkan ramuan ke kain bersih dan ikat dengan tali, kemudian masukkan ke dalam cuka hangat dan oleskan ke seluruh badan agar mempercepat keluarnya keringat.

c. Pegal linu dan rheumatik

Cara pemakaian: jahe diparut 3 rimpang lalu ditempel ke badan yag pegal secukupnya.

\section{Pandan/ Pandanus Amarryllifolius Roxb}

Bagian yang digunakan: Daun

Khasiat dan manfaat: 
a. Bahan pewangi/ aromatherapy

Cara pemakaian: daun pandan direbus lalu daunnya dipakai pewangi

b. Rambut rontok, menghitamkam rambut, menghilangkan ketombe

Cara pemakaian: Daun pandan segar sebanyak 2-5 lembar diiris-iris secukupnya lalu direbus atau diseduh, diminum. Atau daun ditumbuk lalu diperas dan diminum. Pemakaian luar, daun dicuci bersih lalu digiling halus lalu tempelkan pada luka atau kulit kepala yang berketombe.

\section{Kunyit / Curcuma Domestica}

Bagian yang digunakan: rimpang

Khasiat dan manfaat:

a. Luka dan kurap

Cara pemakaian: Rimpang kunyit 1/2 jari, daun asam 1 genggam, air sedikit, dipipis, lalu tempelkan pada luka dan diganti setiap 3 jam.

b. Nyeri haid

Cara pemakaian: Rimpang kunyit 1 jari, ketumbar 7 butir, cengkeh 1 butir, asam kawak, biji pala, campuran ditumbuk ditambah air $110 \mathrm{ml}$, dan dididihkan, kemudian disaring, diminum 1 kali sehari tiap kali minum $100 \mathrm{ml}$.

c. Mencret

Cara pemakaian: Rimpang kunyit $1 / 2$ jari, rasuk angin $1 / 2$ sendok teh, ketumbar 3 biji, buah kayu ules 1 biji, daun trawas 1 helai, campuran ditumbuk ditambah air $115 \mathrm{ml}$ dan dididihkan kemudian disaring, diminum pagi dan sore tiap kali minum $100 \mathrm{ml}$

\section{Daun sirsak/ Annona Muricata}

Bagian yang digunakan: Daun dan buah

Khasiat dan manfaat:

a. Mengobati ambeien

Cara pemakaian: Buah sirsak yang sudah masak, diperas untuk diambil airnya sebanyak 1 gelas, diminum 2 kali sehari.

b. Sakit kandung air seni

Cara pemakaian: Buah sirsak setengah masak, gula dan garam secukupnya, semua bahan tersebut dimasak dibuat kolak, dimakan biasa dan dilakukan secara rutin setiap hari selama seminggu berturut-turut.

c. Bayi mencret

Cara pemakaian: Buah sirsak yag sudah masak diperas dan disaring untuk diambil airnya, diminumkan pada bayi yang mencret sebanyak 2-3 sendok makan.

d. Sakit Pinggang

Cara pemakaian: 20 lembar daun sirsak direbus dengan 5 gelas air sampai mendidih hingga tinggal 3 gelas, diminum 1 kali sehari $3 / 4$ gelas.

e. Bisul

Cara pemakaian: Daun sirsak yang masih muda secukupnya ditumbuk halus dan ditambah $1 / 2$ sendok air, diaduk sampai merata, ditempelken pada bagian bisul.

7. Daun Jambu/ Psidium Guajava

Khasiat dan manfaat:

a. Disentri

Cara pemakaian: Daun jambu biji 6 gram, kayu secang 1 gram, rasuk angin 1 gram, daun patikan cina 5 gram, daun pegagan 7 gram, kayu ules 2 buah, kayu ules 2 buah, bawang merah 1 umbi, air $120 \mathrm{ml}$. Dibuat Infus diminum 2 kali sehari (pagi dan sore) tiap kali minum $100 \mathrm{ml}$ diulang selama 4 hari. 
b. Mencret

Cara pemakaian : Daun biji jambu muda 9 helai, kunyit 1 jari, biji kedawung (disangrai) 4 butir, rasuk angis 4 gram, air $100 \mathrm{ml}$, dibuat infus, diminum 2 kali sehari, tiap kali minum $100 \mathrm{ml}$ diulang selama 4 hari.

c. Daun Kunci

Khasiat dan manfaat Kunci:

Untuk memulihkan pasien pasca melahirkan, cara pemakaiannya adalah diambil akar secukupnya dicampu dengan kunir, lengkuas, dan kacang ditumbuk sampai halus lalu dimakan.

8. Mahkota Dewa / Phaleria Macrocarpa

Khasiat dan manfaat:

a. Mengobati tumor, kanker, disentri, psoriasis, jerawat, penyakit kulit bahkan penyakit ganas lainnya.

Cara pemakaian: buahnya di kupas, diiris lalu dijemur, kulitnya diambil 1 ons direbus lalu diminum. (Belum diketahui dosis efektif yang aman dan bermanfaat) maka untuk obat yang diminum, gunakan irisan buah kering (tanpa biji). Selama beberapa hari baru dosis ditingkatkan sedikit demi sedikit, sampai dirasakan manfaatnya. Untuk penyakit berat seperti kanker dan psoraisis, dosis pemakaian kadang harus lebih besar agar mendapat manfaat perbaikan. Perhatikan juga efek samping yang timbul dari pemakaian tumbuhan ini.

9. Kumis Kucing/ Orthosiphon aristatus (B1) Miq.)

Khasiat dan manfaat

a. Kencing batu, peluruh air seni, infeksi ginjal dan infeksi kandung kemih Cara pemakaian : 30-60 gr (kering) atau 90-120 (basah) direbus, atau yang kering/ basah diseduh sebagai teh, diminum 2 kali sehari pagi dan sore.

10. Daun Sembung / Blumea Balsamifera

Khasiat dan manfaat:

a. Meningkatkan empedu

Cara pemakaian: Daun sembung 4 helai, air $110 \mathrm{ml}$ direbus sampai mendidih diminum 1 kali sehari $100 \mathrm{ml}$.

b. Salesma

Cara pemakaian: Daun sembung 5 helai, daun sembukan 1 genggam, air 110 $\mathrm{ml}$, dibuat infus atau dipipis, diminum 2 kali sehari, tiap kali minum $100 \mathrm{ml}$ apabila dipipis diminum 2 kali sehari dan tiap kali minum $1 / 4$ cangkir.

c. Demam

Cara pemakaian: Daun sembung secukupnya, air 1 panci, direbus sampai mendidih lalu basahi handuk dengan ramuan tersebut kemudian gunakan untuk membasuh badanm muka, kaki dan tangan.

\section{Kencur/ Kaemferia Galanga}

Bagian yang digunakan: rimpang/ akar

Khasiat dan manfaat:

a. Masuk angin/ sakit kepala/ radang lambung

2 rimpang kencur sebesar ibu jari dikuliti sampai bersih dan dikunyah; ditelan airnya dan dibuang ampasnya kemudian minum segelas air putih lalu diulangi sampai sembuh.

b. Batuk/ menghilangkan darah kotor/ diare

1 rimpang kencur sebesar ibu jari dan garam secukupnya, kencur diparut kemudian ditambah 1 cangkir air hangat, diperas dan disaring. Diminum dengan ditambah garam secukupnya. 
c. Keseleo

2 rimpang kencur digerus/ ditumbuk sampai halus lalu ditempel ke bagian tubuh yang keseleo.

12. Katuk / Sauropus Androgynus

Bagian yang digunakan: Daun

Khasiat dan manfaat:

a. Memperlancar ASI

Untuk memperlancar ASI, 200 gram daun katuk direbus dengan 1,5 gelas air selama 15 menit, setelah dingin disaring lalu diminum, bisa juga dibuat sayur lalu dimakan.

b. Obat bisul

Untuk bisul, daun segar dilumatkan, tempelkan ke bagian yang sakit.

13. Ceremai / Pyillanthus Acidus

Khasiat dan manfaat:

a. Sembelit

Cara pemakaian: siapkan biji ceremai sebanya $3 / 4$ sendok teh, dicuci lalu digiling sampai halus. Seduh dengan $1 / 2$ cangkir air panas. Sewaktu masih hangat tambahkan 1 sendok makan madu, aduk sampai merata kemudian diminum sekaligus, lakukan 2 kali sehari.

b. Asma

Cara pemakaian: Siapkan biji ceremai sebanyak 6 biji, bawang merah 2 butir, akar kara $1 / 2$ genggam, buah lengkeng 8 butir, dicuci lalu ditumbuk seperlunya. Bahan-bahan tersebut lalu direbus dengan 2 gelas air bersih sampai tersisa $1 \frac{1 / 2}{2}$ gelas. Setelah dingin disaring lalu diminum dengan air gula secukupnya, sehari 2 kali masing-masing 3/4 gelas.

c. Kanker

Cara pemakaian : Siapkan daun ceremai yang masih muda sebanyak $1 / 4$ genggam, daun belimbing $1 / 3$ genggam, bidara upas $1 / 2$ jari, gadung cina $1 / 2$ jari gula enau 3 jari, dicuci lalu dipotong-potong seperlunya. Bahan-bahan tadi direbus dengan 3 gelas air bersih sampai tertinggal $3 / 4$ bagian, setelah dingin disaring, siap untuk diminum. Sehari 3 kali, masing-masing cukup $3 / 4$ gelas.

\section{Meniran /Pyillanthus Niruri}

Bagian yang digunakan: seluruh tanaman

Khasiat dan manfaat:

a. Peluruh dahak dan penambah nafsu makan.

Caranya adalah: 30-60 gram meniran direbus dalam 3 gelas air hingga tersisa 1 gelas. Setelah dingin disaring lalu diminum.

b. Mengobati luka dalam setelah melahirkan/ pendarahan dan mengobati kista Cara pemakaian: 3 tangkai daun meniran yang tinggi/ sudah besar direbus

15. Karuk dengan akarnya lalu diminum airnya.

Khasiat dan manfaat daun karuk, untuk mengobati sesak nafas, cara pemakaian

\section{Binahong} daun karuk dan suliga ditumbuk lalu digosok ke bagian dada.

Khasiat dan manfaat daun binahong, untuk mengobati segala macam penyakit, khususnya lambung atau diabet, caranya 7 lembar binahong di jus disaring lalu diminumWera/ kembang sepatu.

Khasiat dan manfaat wera, untuk mengobati batuk rejang, caranya 5 kembang wera diambil diperas disaring lalu dicampur air hangat kemudian diminum.

\section{Tempuyungan}

Khasiat dan manfaat tempuyungan untuk mengobati nyeri pinggang, caranya 3 helai daun dijemur lalu direbus, diseduh diminum 2 kali sehari pagi dan sore. 


\section{Korejatangi}

Khasiat dan manfaat korejatangi untuk mengobati mata merah/ bengkak, caranya bunga korejatangi dipetik lalu dimasukan ke dalam air, setelah itu teteskan ke mata 2 sampai 3 tetes sehari 3 kali.

\section{Jaringao}

Khasiat dan manfaat jaringao untuk mengobati luka lebam/ bengkak atau keseleo,

20. Sidaguri caranya diambil diparut di jus dengan bakung lalu ditempel ke bagian tubuh yang luka

a. Perut mulas, cara pemakaianya: akar dan jahe dikunyah lalu ditelan airnya

b. Rheumatik, cara pemakaiannya: seluruh tumbuhan termasuk akar sebanyak 60gr kering, direbus lalu diminum airnya.

c. Sakit gigi, cara pemakaiannya: akar dikunyah

d. Sengatan lebah, cara pemakaiannya: bunga dilumatkan lalu ditempel

\section{Lampeni}

Khasiat dan manfaat lampeni untuk mengobati lambung/ radang usus, sembelit, dan mag caranya buahnya yang sudah masak berwarna hitam

\section{Seupan Lentah} sebanyak $1 / 2$ ons langsung dimakan.

Khasiat dan manfaat seupan lentah untuk mengobati perut kembung bagi anak yang masuk angin caranya ambil 3 pucuk daun dicampur dengan 3 cabe rawit dan 3 lembar daun kahitutan ditumbuk lalu dioleskan ke perut atau ke badan.

\section{Pipicisan}

Khasiat dan manfaat pipicisan untuk menurunkan kadar gula/ diabet dijus

\section{Panglay} 1ons dicampur air lalu diminum tiap pagi dan sore.

Khasiat dan manfaat panglay untuk mengobati:

a. Jantung lemah : panglay diparut lalu hasil parutannya direbus dengan air dan diminum secara teratur setiap sore.

b. Sakit kepala: parut rimpang panglay yang telah dicuci, lalu hasil adonan dicampur air agar seperti bubur lalu ditempel pada pelipis atau dahi.

c. Sakit kuning: parut rimpang panglay sebanyak $1 / 2$ jari saring lalu campur sedikit air dan satu sendok makan madu. Dosis minumnya 2-3 kali sehari hingga sembuh.

d. Rheumatik : cuci bersih dan parut sejumlah rimpang panglay, hasil parutan campur air hingga menjadi bubur untuk dibalurkan pada bagian sendi yang terasa sakit.

e. Cacingan : iris atau tumbuk halus rimpang panglay lalu rebus bersama dengan temu hitam, ketumbar, dan tangkai daun sirih. Setelah dingin airnya rebusan disaring lalu diminum.

f. Gatal-gatal/ kaligata : cuci bersih panglay lalu diparut, setelah itu oleskan ke bagian tubuh yang gatal.

\section{PENUTUP}

\section{Simpulan}

Kearifan lokal dalam pengobatan tradisional baik itu pengobatan menggunakan hikmah, pijat, jasa paraji, atau menggunakan herbal/ tumbuh-tumbuhan di Desa Lumbungsari Kecamatan Lumbung memang bermanfaat bagi kesehatan, dan kini digencarkan penggunaannya karena lebih mudah dijangkau masyarakat, baik harga 
maupun ketersediaannya. Obat tradisional pada saat ini banyak digunakan karena menurut beberapa penelitian tidak terlalu menyebabkan efek samping, karena masih bisa dicerna oleh tubuh. Penggunaan bahan alam, baik sebagai obat maupun tujuan lain cenderung meningkat, terlebih dengan adanya isu back to nature serta krisis berkepanjangan yang mengakibatkan turunnya daya beli masyarakat. Obat tradisional dan tanaman obat banyak digunakan masyarakat menengah ke bawah terutama dalam upaya preventif, promotif, dan rehabilitatif. Sementara ini banyak orang beranggapan bahwa penggunaan tanaman obat atau obat tradisional relatif lebih aman dibandingkan obat sintesis.

Terdapat 4 macam kearifan lokal dalam penggunaan pengobatan tradisional yang terdapat di Desa Lumbungsari Kecamatan Lumbung, di antaranya pengobatan hikmah, jasa pijat, jasa dukun beranak/ paraji,atau menggunakan ramuan herbal/ tumbuh-tumbuhan. Ramuan tersebut didapat dari hasil observasi dan deskripsi kepada narasumber atau pengguna ramuan pengobatan tradisional, adapun bagian yang bisa dimanfaatkan dari tumbuh-tumbuhan tersebut untuk dijadikan pengobatan tradisional adalah akar, rimpang, batang, buah, daun dan bunga.

Berikut ini 4 rangkaian penggunaan dalam pengobatan tradisional yang dideskripisikan di desa Lumbungsari kecamatan Lumbung yakni:

1) Pengobatan tradisional dengan menggunaan metode ilmu hikmah.

Adapun deskripsi pengobatan yang bisa ditangani adalah:

1) Sakit lambung

2) Kerasukan Jin

3) Susah meninggal

4) Kehilangan barang

5) Bagi yang susah melahirkan

6) Anak yang sering menangis atau demam

7) Amalan khusus bagi pasien

8) Bagi yang ingin dunia/ mempunyai hajat/ keperluan

9) Membuka kunci/ gembok

10) Menaklukkan orang yang keras kepala/ bengal

11) Jika maksud ingin tercapai

12) Pelet/ asihan

13) Mengobati penyakit eksim

14) Jika ingin disayangi pimpinan/ atasan

15) Jika ingin tidak gentar terhadap musuh

16) Agar tidak grogi ketika akan pidato

17) Bagi yang ingin cepat punya keturunan

18) Ingin dimudahkan jodohnya

19) Jika ingin menang dalam berdebat

20) Jika ingin menahan hujan/ ingin kesenangan dunia

2) Pengobatan tradisional dengan menggunakan jasa dukun beranak/ paraji

Adapun deskripsi pengobatan yang bisa ditangani adalah :

1) Jika ingin punya anak

2) Jika ingin kuat dalam hubungan suami isteri/ kejantanan

3) Mengobati keputihan

4) Jika ada yang susah dalam melahirkan

5) Jika ada anak/ bayi yang sakit panas/ demam

6) Jika ada anak/ bayi yang mencret

7) Jika ada anak/ bayi yang suka menangis tanpa sebab/ atau anak ingin pintar, menurut/ patuh pada kedua orang tua 
8) Jika ada anak/ bayi yang susah makan

9) Jika ada anak yang ingin disapih

3) Pengobatan tradisional dengan menggunakan jasa pijat.

Adapun deskripsi pengobatan yang bisa ditangani adalah :

1) Ahli dalam memijat

2) Hikmah (Pembuka Kunci)

3) Untuk melepas Roh (ketemu diri)

4) Pembuka Bumi

5) Mandi Awet Muda

4) Pengobatan tradisional dengan menggunakan herbal/ tumbuh-tumbuhan Adapun tumbuhan yang digunakan adalah :
1) Pala
14) Ceremai
2) Lengkuas/Laja
15) Meniran
3) Jahe
4) Pandan
5) Kunyit
6) Daun sirsak
16) Karuk
7) Daun jambu
17) Binahong
18) Wera/ kembang sepatu
8) Kunci
9) Mahkota dewa
19) Tempuyungan
10) Kumis kucing
11) Daun sembung
20) Korejatangi
12) Kencur
13) Katuk
21) Jaringao
22) Sidaguri
23) Lampeni
24) Seupan lentah
25) Pipicisan
26) Panglay

Agar pengobatan tradisional ini berkembang dan banyak digunakan oleh masyarakat dapat melibatkan secara aktif stakeholders baik pemerintah maupun non pemerintah dan harus disokong oleh sarana dan prasarana yang memadai, selain itu perlu juga adanya strategi pengembangan dan evaluasi secara berkala.

\section{Saran}

1. Diperlukan penelitian secara integratif terhadap pengobatan tradisional di Desa Lumbungsari Kecamatan Lumbung.

2. Diperlukan kebijakan dan anjuran Pemda dan Dinas Kesehatan terkait agar pelayanan kesehatan selain menggunakan obat-obatan dari pos pelayanan kesehatan juga dapat menggunakan obat-obatan herbal yang tumbuh di sekitar kita.

3. Diperlukan kebijakan Pemda (dinas kesehatan) yang mengharuskan pengobatan tradisional dijadikan budaya dan ciri khas suatu daerah.

4. Diperlukan ikon pengobatan tradisional yang mempresentasikan kebudayaan dan kekhasan Desa Lumbungsari Kecamatan Lumbung. Dalam hal ini pengobatan tradisional dianggap tepat untuk menjadi ikon Desa Lumbungsari Kecamatan Lumbung disebabkan banyaknya tumbuhan herbal atau apotik hidup yang ditanam masyarakat di lingkungan mereka. Namun dari segi kuantitas, pengobatan tradisional herbal masih jauh dan kurang banyak digunakan bila dibandingkan obat-obatan yang berbahan kimia, atau yang dijual di warung-warung, akan tetapi pengobatan tradisional herbal mencerminkan dinamika kehidupan masyarakat Desa Lumbungsari Kecamatan Lumbung yang berkarakter, realitas, dan perubahan masyarakat yang dinamis. 


\section{UCAPAN TERIMA KASIH}

Ahamdulillah, atas ridla dan maghfirah-Nya penelitian ini akhirnya dapat terselesaikan, tentunya penulis sangat menghaturkan banyak terima kasih kepada pihak-pihak yang telah banyak membantu khusunya :

1. Kepala Desa Lumbungsari beserta jajaran pemerintah desa Lumbungsari.

2. Bapak Kuwu Maman, bapak Yayan, dan Ibu Ining selaku narasumber pengobatan tradisional di desa Lumbungsari.

3. Bapak Adjat, selaku narahubung penulis dengan narasumber.

4. Semua orangyang terlibat dalam penelitianini, kami tidak dapatmenyebutkannya satu-persatu, terimakasih atas segala kebaikan dan bantuannya.

\section{DAFTAR SUMBER}

Argadipraja, R. Duke. (1992). Babad Panjalu Galur Raja-raja Tatar Sunda. Bandung: Mekar Rahayu.

Atlas Indonesia E Dunia Edisi 33 Propinsi di Indonesia. (2000). Jakarta. Pustaka Sandro. Ayatrohaedi. (2005). Sundakala: Cuplikan Sejarah Sunda Berdasarkan Naskah-naskah "Panitia Wangsakerta" dari Cirebon. Jakarta: Pustaka Jaya.

Depkes RI. (2004). Farmakognosi. Jakarta. Pusdiknakes.

Ekadjati, Edi S. (1977). Wawacan Sajarah Galuh. Bandung: EFEO.

Ekadjati, Edi S. (2005). Polemik Naskah Pangeran Wangsakerta. Jakarta: Pustaka Jaya.

Hartatik, Sri. (2011). Herbal dan Pijat Refleksi. Surabaya. Bintang Usaha Jaya.

Hidayat, Yayat. Mengenal Warisan Kerajaan Panjalu. Artikel Majalah Misteri Edisi 20 Peb - 04 Mar 2010.

Iskandar, Yoseph (1997). Sejarah Jawa Barat: Yuganing Rajakawasa. Bandung: Geger Sunten.

Sazzaki, Ridia. (2011). Resep Obat Herbal dan Pijat Refleksi. Jakarta. Bintang Indonesia. Suganda, Her. Situ Lengkong dan Nusalarang, Wisata Alami yang Islami. Artikel Harian Kompas, 21 Juni 2003.

Suganda, Her. Naskah Sunda Kuno Antara Sejarah dan Nilai Sakral. Artikel Harian Kompas, 24 Mei 2008.

Suhendar, R, Hendar. (2007). Sang Hyang Borosngora. Panjalu. CV. Borosngora.

Sutarwan, Aam Permana. Gus Dur "Merevisi" Sejarah Situ Lengkong Panjalu, Air Situ Lengkong berasal dari Mekah. Artikel Harian Pikiran Rakyat, 10 Juli 2000.

Sumaryadi, Sugeng/Eriez M Rizal. Menengok Rahasia Sukses Warga Panjalu. Artikel Harian Media Indonesia, 13 Maret 2004.

Sumaryadi, Sugeng. Sejarah Panjang yang Terus Dikenang. Artikel Harian Media Indonesia, 13 Maret 2004. 